\title{
Knowledge Management in Multi-Party IS Development Teams -A Case Study at Fudan University
}

\author{
Liang Song (Corresponding author) \\ Lally School of Management and Technology, Rensselaer Polytechnic Institute \\ $1108^{\text {th }}$ Street, Troy, New York 12180, United States \\ Tel: 1-518-892-8098_E-mail: songl@rpi.edu \\ Chenghong Zhang \\ School of Management, Fudan University \\ 200 Handan Road, Shanghai 200433, China \\ Tel: 86-21-25011233Ｅ-mail: chzhang@fudan.edu.cn \\ Yantao Wang \\ School of Economics and Management, NorthEast Dianli University \\ 169 Changchun Road, Jilin City, Jilin Province 132012, China
}

Tel: 86-13843226310Ｅ-mail: wangyantao@mail.nedu.edu.cn

Limin Lin

School of Management, Fudan University

200 Handan Road, Shanghai 200433, China

Tel: 86-21-65642222Ｅ-mail: Imlin@fudan.edu.cn

\begin{abstract}
This paper describes how a unique type of information system development team, deploying a computer-mediated collaborative technology, developed a highly complex information system. The uniqueness of the team, what we call MISD teams, (Multi-Party Information System Development teams) was derived from the fact that they were inter-organizational and engaged in knowledge management among five parties with the highly complicated task of information system development. Existing research on knowledge management does not fully address the challenges of such MISD teams. Using the case of Fudan University, we describe the behavior of the members of a MISD team to seek implications regarding knowledge management focusing on teams within the emerging contexts such as the one we observed. The data we collected also allowed us to identify successful managerial practices
\end{abstract}




$\begin{array}{rr}\text { Macrothink } & \text { International Journal of Management Innovation Systems } \\ \text { ISSN 1943-1384 } \\ \text { 2009, Vol. 1, No. 2: E3 }\end{array}$

and develop recommendations for managers responsible for such teams.

Keywords: Knowledge management, Information system development 


\section{Macrothink \\ International Journal of Management Innovation Systems \\ ISSN 1943-1384 \\ 2009, Vol. 1, No. 2: E3}

\section{Introduction}

Suppose an information system development team must totally complete a gigantic information system for a very intricate environment in four months. One might assume that together, a customer party and a development party can achieve this goal. However, the customer party is not particularly adept at information system development and has no previous experience regarding it nor can they communicate efficiently with the development party. Another party must be involved as a bridge between the customer party and the development party. Additionally, as this is a complex project, there must be a fourth party, a professional party, to monitor the entire information system development process and provide assistance to the customer party. Since the development party employs a large staff and all of those involved can't come to one site for development, the development party is divided into two sections, one of which must communicate with the others via electronic media. We call these teams partly Virtual Multi-Party Information System development teams (or MISD teams).

How does the team facilitate knowledge sharing in such an environment where there is no common history to establish knowledge sharing norms. Knowledge Management becomes a crucial issue in achieving an organization's objective (Hackbarth 1998). Thus, further research to understand how to effectively ensure knowledge sharing in team situations will contribute to fulfilling this information system development team's goals.

\section{What Does the Knowledge Management Literature Suggest for Managing a MISD Team?}

Research regarding knowledge management (Nonaka and Takeuchi, 1995) has typically examined cross-functional teams within firms. Research concerning knowledge management in complex multi-party cross-organizational teams is quite limited, especially when the teams undertake a non-routine task such as information system development. Existing research has generally focused on managing a firm, an organization or a team. Examples include determining the best strategy for managing knowledge (Hanson, Nihria, and Tierney, 1999), the principles of knowledge management (Thomas, 1997), and methods to increase innovativeness and responsiveness (Hackbarth, 1998).

Only a small subset of this research has focused on knowledge sharing in multi-party inter-organizational complex teams articulating norms developed for sharing, the types of knowledge content shared, and the effect of knowledge sharing practices on team outcomes. Since inter-organizational teams are always temporary, empirical studies have shown that while the teams create knowledge and learn, they also forget (i.e., do not remember or lose track of acquired knowledge) (Argote, Beckman, and Epple, 1990; Darr, Argote and Epple, 1995). Thus, the storage, organization, and the retrieval of organizational knowledge, also referred to as organizational memory (Stein and Zwass, 1995; Walsh and Ungson, 1991), constitute an important aspect of effective organizational knowledge management. At the 
same time, IT plays an important role in knowledge sharing by extending the individual's reach beyond traditional communication lines. For instance, individuals are unlikely to encounter new knowledge through their close knit work networks as individuals in the same clique tend to possess similar information (Robertson, Swan, and Newell, 1996). IT, such as computer networks, electronic bulletin boards, and discussion groups, can expand the individual's network to a more extended, although perhaps weaker, connection to the central knowledge diffusion process by exposing them to new ideas (Robertson et al., 1996).

Underlying these findings is the long held recognition that effective electronically-mediated communication, collaboration, and coordination rest on a shared understanding among team members regarding the problem, norms (of knowledge capture, sharing, and use; of work distribution; and of roles and responsibilities), and context for interpreting knowledge (Clark, 1996; Clark and Brennan, 1991, 1993; Davenport and Prusak, 1997; Dougherty, 1992; Krauss and Fussell, 1990; Madhaven and Grover, 1998; Marshall and Novick, 1995).

For teams in an organization or simple inter-organization teams, there is a very easy way to establish a shared understanding among team members. When team members come from one organization, they may share a common set of norms, context, and problem definitions or have worked at similar tasks. For the simple inter-organization teams, while team members may not have a shared understanding before this assignment, a single collocated meeting may be feasible if the team's task is constrained to a limited set of possible solutions using a known decision making process. In this single meeting, the roles and responsibilities for every team member, the solution space, and the decision process can be defined and the team members can disperse to their respective tasks.

When the task is information system development, which is usually highly innovative and unstructured as is the case with MISD teams, the methods used to create shared understanding for teams whose tasks can be restrained to a limited scope and follow routine work processes may not apply. Information system development as a special and highly professional task is substantially different from routine problem-solving in the following ways: 1) solutions require the synthesis of domain professional knowledge such as knowledge of programming, 2) finding a solution is an iterative procedure, 3) collaboration in problem solving is a must, 4) solutions are generated in unpredicted ways, and 5) problems are often not well specified, being understood only as they are solved (Sage, 1992).

These characteristics of information development teams suggest that knowledge management and the knowledge management system of those teams must be somewhat different than the teams whose tasks are routine and can be solved without innovative work. Moreover, when the teams with a very innovative task require the involvement of more and more parties, they become extremely complex as is the case with MISD teams. Knowledge management and the knowledge management system of those teams will be distinctive with each new challenge undertaken by the MISD teams. 
The opportunity to observe a MISD team over time allowed us to address certain fundamental questions regarding how to manage the knowledge sharing process in MISD teams:

1. In what way does a team involving five parties need to be organized to become an efficient knowledge sharing organization? How are roles defined?

2. In what way can a coordination protocol be established and adapted to suit the knowledge sharing needs of a VMISD team?

3. How does the team ensure that team members have an overview about the project?

4. What steps can be taken or roles created to make sure that appropriate knowledge is stored in the best possible manner for future retrieval and is accessible to team members with minimum search effort? How should this knowledge be described in order to benefit all?

These are some of the issues that were addressed by Fudan University and several other parties in a MISD team. The team succeeded beyond management's expectations. The authors of this paper were fortunate to be able to observe the team closely throughout its four-month life and learn how the team eventually addressed these issues. It is their story to which we now turn.

\section{The Case of Fudan University}

The team was initiated by Fudan University, one of the most famous universities in China, to contrive a new information system to replace its old one. Due to the complexity of the system and the time limit (four months), an "INFORMATION OFFICE" comprised of experienced professionals was founded to take charge of this particular project. As the representative of the Fudan administration layer, the INFORMATION OFFICE became a major party of the MISD team.

The other four parties of the MISD team were soon determined by the INFORMATION OFFICE. The second party is SUPERVISING PARTY, whose members are professors and graduate students from the Information Systems Department. Their duties were to decrease the quality risk by supervising the development process. The third party was the end users, such as the directors and staff from the Human Resource Office of Fudan University.

The fourth and the fifth parties are the software developing parties. Since WISCOM, the software company, was located in Nan Jing City 400 miles from Fudan University, the project team moved to Fudan while other facilities such as the Quality Control area remained in Nan Jing. In this paper, they were defined the fourth party and the fifth party.

The members of the five parties in this team had never worked together on previous projects 
regarding intricate information system development and did not have a common set of norms for project coordination. The team worked full time for four months on this project and faced many challenges. They needed to acquire additional requirements for the information system from various consumer areas of Fudan University, which were never originally queried, and arrive at some agreement regarding what this future information system would entail. The team consisted of people from different disciplines, work experiences, and organizations who had never worked together. Finally, they must develop an original information system to meet these requirements in a critically short time period to attain this team's goal.

\section{A Multi-Party Information System Development Team: The Success Story}

Despite these challenges, the team was a runaway success. The team successfully designed and developed a complete and successful information system within budget in only four months, instead of the typical ten months, with more than a $50 \%$ reduction in total development time when compared to traditional teams. On the basis of a formal technical review at the end of this project by three experts, this project was judged to be successful having attained its objectives.

Fortunately, we were able to closely trace the lifecycle of the team using several data collection methods: 1) ethnographic observation, 2) questionnaire surveys, 3) interviews, 4) group meetings, and 5) logs of collaborative technology usage. Two of the study authors became participant observers as members of the supervising party in the team's process, attending 20 group meetings and analysing 89 catalogues in the VSS (visual source safe) as a collaborative technology. These catalogues stored documents of the information system development and all the meeting minutes as well as supervising documents by the supervising party. The log of the activity of the team members using VSS were examined to determine which functions of the technology team members used. Finally, a lessons-learned session was conducted with members of the information office and the supervising party.

Patterns across these data were investigated to identify those management practices that seemed to contribute to the success of this team. We found three such practices were necessary in order for this MISD team to succeed:

1. Role definition and strategy setting: clearly establishing each party's responsibility and duty,

2. Technology use: using collaborative technology to contribute to knowledge management (e.g., knowledge sharing, knowledge storing, and knowledge creation),

3. Work restructuring: restructuring work to facilitate knowledge management.

We elaborate on each of these management practices using examples from our case to illustrate our points. 
4.1. Management Practice 1: Role Definition and Strategy Setting: Clearly Establishing Each Party's Responsibility Prior to the Information System Development Project

Prior to the start of the information system development, even prior to the conceptualization of the MISD team, a senior manager from the information office of Fudan University and a senior manager from WISCOM engaged in a series of discussions and negotiations in which best practices were shared and the composition of the information system development team was discussed. As a result of these meetings, a contract between the top managers from Fudan University and WISCOM was drawn up. This contract defined the contractual obligations between Fudan University and WISCOM regarding project deadlines, project budget, and allocation of liability as well as other items. More importantly, this contract established the composition of the information system development team and declared the formation of the MISD team. It specified the level of participation of each member party of this team, ensuring that one party would not be overwhelmed and each could concentrate on their specific task. For example, the information office's task was to determine the consumer requirements from each consumer department and convey these requirements to the development party in Shanghai. They would additionally convey the recommendations of the supervising party to the development party in Shanghai. The members of the information office didn't need review documents regarding the information system development as that was the supervising party's responsibility. (Figure 1 displays the organization of the team):

1. Provide and illustrate requirements and recommendations

2. Confirm development results

3. Provide development documents

4. Provide recommendations

5. Communicate with each other 


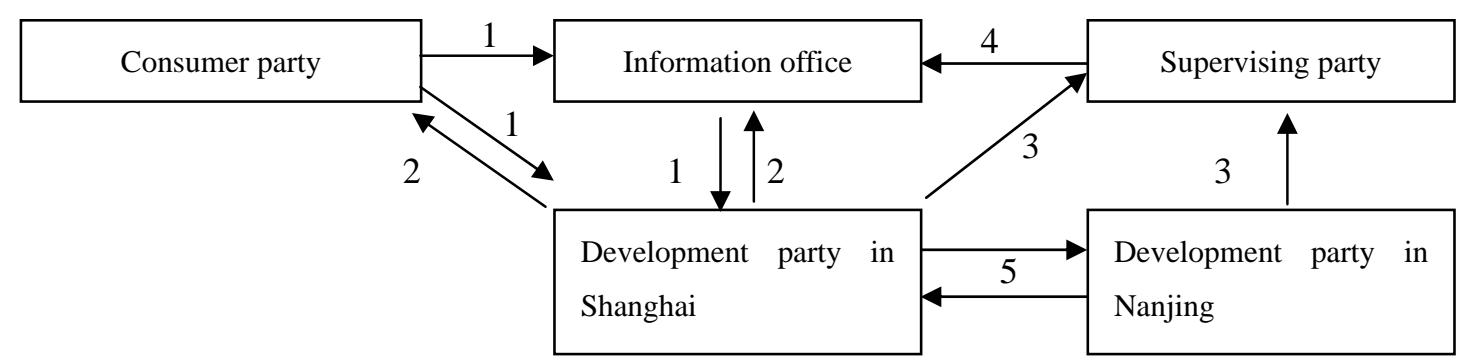

Figure 1. Organization of the Team

Having the agreement in place prior to the information system development proved critical to the success of the team. First, having the agreement in place meant that the staff on each team could openly share information from other parties and not worry about management's concern regarding the sharing of information. Second, since it definitely established each party's task and concretely demonstrated what information must obtained, each party had a clear understanding regarding what it was responsible for to complete its task and which party it should contact to obtain the information it needed. It was important to note that each party didn't necessarily need every piece of information about the project to meet their goals. Finally, this agreement set forth a basic work process with room for future adjustments.

\subsection{Management Practice 2: Collaborative Technologies are Knowledge Management Technologies}

The team's collaborative technology, the VSS (visual source safe), were main knowledge management tools in this project. The VSS was a mature tool for collaboration provided by Microsoft. It allowed secure common file storage of classified files to be accessed by the staff. It also helped manage projects, regardless of the file type (text files, graphics files, binary files, sound files, or video files) by saving them to a database. When someone needed to share files between two or more projects, they could share them quickly and efficiently. When a file was added to VSS, the file was backed up on the database, made available to other staff members, and changes that had been made to the file were saved so an old version could be recovered at any time. Members of the team could see the latest version of any file, make changes, and save a new version in the database.

Prior to the use of these collaborative technologies, creating a coordination protocol (see the box Technology Enabler: Coordination Protocol) for facilitating collaborative use was the focus of early discussions. The protocol the team developed made team members change the way they normally worked with others in fundamental ways: from primarily face to face discussions to use of collaborative technology to aid in knowledge sharing and the exchange of thoughts; from storing documents in various places to making all of the documents available in one place, the VSS; from controlling the document versions by hand to manipulating them with technology. Thus, members of this team could review all the documents regarding this project in VSS and shared comfortably share them amongst 
themselves.

\begin{tabular}{|c|}
\hline Technology Enabler: Coordination Protocol \\
\hline $\begin{array}{l}\text { Define various catalogues in VSS for specific aims or for certain staff and illustrate } \\
\text { which documents should be stored. }\end{array}$ \\
\hline $\begin{array}{l}\text { Receive training on the use of the VSS prior to information system development so } \\
\text { time during work would not be spent in training. }\end{array}$ \\
\hline $\begin{array}{l}\text { Create and use notification profiles so that each person would be informed when } \\
\text { new file were created or modified. }\end{array}$ \\
\hline $\begin{array}{l}\text { Use templates for agendas, minutes of meetings, and information system } \\
\text { development documents so that every file can be easily understood. }\end{array}$ \\
\hline Every document must be stored in VSS on time on the basis of the plan. \\
\hline $\begin{array}{l}\text { Take time before meeting to scrutinize other party's files and documents (to } \\
\text { encourage the asynchronous work on the project and appropriate preparation for } \\
\text { meetings). }\end{array}$ \\
\hline Use the VSS for all knowledge sharing needs (including, for example, file sharing). \\
\hline Documents in the catalogue of certain staff are not valid to be a for \\
\hline
\end{tabular}

After some time, some problems regarding managing knowledge appeared in the coordination protocol and some critical modifications were exerted to accommodate knowledge management issues.

One such example of modifications to the coordination protocol to accommodate knowledge management issues was that at the outset, the protocol didn't define specifically how the documents were to be written. It was easily understood when a document described the requirements from the consumer department. Nevertheless, when a document described how to organize the information system and the mainframe of this information system, it could be very technical causing some confusion among the staff. Since knowledge in information system development is very technical and confined in a specific domain, a standard language, UML (unified model language) (see the box: What is UML) was introduced to represent knowledge in this project. Through UML, knowledge conveyed among the staff could be easily understood in a short period of time. UML is also a standard language for a design tool, Rational Rose, which is a fairly powerful tool to write information system development documents and facilitate future document modification.

\section{What is UML?}

The Unified Modelling Language ${ }^{\mathrm{TM}}$ (UML) is the industry standard language for specifying, visualizing, constructing, and documenting the artefacts of software systems. It simplifies the complex process of software design making a "blueprint" for construction. 
Another example of the need to modify its coordination protocol to accommodate knowledge management issues was the protocol that insisted that documents in the catalogue of certain staff were not valid as a formal document since members of the development party often stored their unfinished documents in their personal catalogues. However, over time, the team began to realize that the unfinished documents were also valuable as they reflected the development party's original design intention, which could be conveyed to the supervising party. Thus, the supervising party could make recommendations to contribute to the information system design instead of making suggestions once the information system design had been completed. From the perspective of knowledge creation, this procedure was fairly critical and could be recognized as a catalyst for knowledge generation.

\subsection{Management Practice 3: Restructure Work to Facilitate Knowledge Management}

In the beginning, the team arrived at an oral agreement to define a basic work process. However, over time, members of this team discovered this basic work process did not meet the requirements for knowledge sharing and should be modified. The team learned that two main work processes should be modified or added to facilitate knowledge sharing:

1. Some staff tries to know the information system by working in the development party.

2. Engage in frequent interaction by group meetings.

4.3.1. Work Restructuring 1: Some staff tries to know the information system by working in the development party.

Though it was very useful to read documents regarding the development of the information system in VSS as a means to understanding it more thoroughly, it was not enough to know everything about the information system due to its complexity. For the future maintenance of this system, understanding something about how this information system was organized and its mainframe was very helpful. However, this only could be achieved by face-to-face communication and observation.

Thus, some staff from the information office joined the development party in Shanghai and took part in some of the coding work of the information system development to acquire first hand knowledge regarding the entire development process. Information development was a highly technical and complex activity that was unstructured and context specific, knowledge that was not easily assimilated by other individuals who were not real developers. Therefore, tacit knowledge to tacit knowledge was the best way to glean information instead of explicit knowledge to tacit knowledge.

\subsubsection{Work Restructuring 2: Engage in Frequent Interaction by a Group Meeting}


In the beginning, after several group meetings attended by the five parties to reach an oral agreement, this type of meeting including all of the stakeholders was not held as collaboration was difficult. Most meetings were held between two or three parties. For example, a meeting was held between the supervising party and the development party to discuss some problems regarding development documents. However, over time, some parties began to feel left out and solving some issues required three or four parties collaborating. For instance, the information office didn't wish to know everything regarding technological aspects of the project, but they wanted to a general overview. Additionally, when the development party wanted to review operations requirements, they had to contact the operation party through the information office and provide their plan of review to the supervising party.

In response, a group meeting was held every Tuesday morning. The development party, the information office, and the supervising party were required to attend and the operation department's participation was optional. In this meeting, information about this project was reported by the development party, so the other parties would have a general overview about this project and troubleshooting could be discussed.

In sum, we found that the team was able to function more successfully because it changed its work processes. Restructuring the work with the MISD teams was dependent the fact that that the MISD teams were partly Virtual Multi-Party Information System Development teams.

\section{Implications for Research}

As with any case study, the generalizability of the results can only be assessed by observing other similar cases and by applying theory to illustrate the behavior patterns. Thus, the first implication of this research for future study is to encourage researchers of organization knowledge management to examine teams varying in level of complexity. If these findings are supported in future research, they suggest that an important factor in determining how knowledge is shared in organizations is the complexity of the team. Highly complex teams, which involve three or more parties from various organizations, need initial knowledge management strategy and role definition. This is not the case in comparatively simple teams. In multi-party complex teams, since the knowledge required for success is such that it can't be fully understood by one party, each party must acquire their specific knowledge on basis of their individual roles. This is not consistent with research from other scholars such as Nonaka, Reinmoeller, and Senoo (2000) who imply that knowledge in one organization should be fully shared by members in the other organization. Why the difference between our findings and those in the extant literature? One explanation might be that full knowledge sharing means any knowledge in one organization can be obtained at any time, but members in the organization may not have a need to obtain all of the knowledge and only use what they need to know based on their roles.

This study offers another implication for future research. For teams with a highly technical 
and unstructured task like information system development, they must find a balance between a "people-to-documents" approach and a "people-to-people" approach for knowledge management at various stages of development. In this case's initial stage, documents in VSS were a principal way of conveying knowledge and a "people-to-documents" approach outweighed a "people-to-people" approach. However, in the later stages, a "people-to-documents" approach took a lower priority as was demonstrated by the decreasing usage in VSS as portrayed by the log files. Future research is required to determine the best balance between each approach according to the level of task complexity in various stages of the project.

Finally, this case clearly raised research questions regarding the structure of knowledge management systems for information system development, particularly for development using VMISD teams. Nonaka et al. (2000) reported that the literature suggests, "Large companies with a high degree of internal complexity need the assistance of information technology." This case confirms that IT can play an important role to facilitate knowledge management in complex organizations. That UML was used as a standard language representing knowledge in this case may be an implication for future research regarding how knowledge can be effectively represented in KMS for teams whose task is confined in a specific domain.

Features such as knowledge capturing and automatic categorization of knowledge are not fully involved in the technology of this case. Future research is required to determine to what degree these additional features will help to solve the knowledge management problems encountered by the team. 


\section{References}

Argote, L., Beckman, S., \& Epple, D. (1990). The persistence and transfer of learning in industrial settings. Management Science, 36, 1,795-1,763.

Clark, H. (1996). Using language. Cambridge, England: Cambridge University Press, 56-75.

Clark, H. \& Brennan, S. (1991). Grounding the communication. In L. B. Resnick, J. M. Levine, \& J. S. D. Teasley (Eds.), Perspectives on Socially Shared Cognition, American Psychological Association, ISBN 1557983763.

Clark, H. \& Brennan, S. (1993). Grounding in communication. In R. M. Baecker (Ed.), Groupware and Computer-Supported Cooperative Work: Assisting Human-Human Collaboration. San Mateo, CA: Morgan Kaufmann Publishers, pp. 222-233.

Darr, E. D., Argote, L., \& Epple, D. (1995). "The acquisition, transfer and depreciation of knowledge in service organizations: Productivity in franchises. Management Science, 41(11), $1,750-1,762$.

Davenport, T. H. \& Prusak, L. (1997). Working knowledge: How organizations manage what they know. Boston, MA: Harvard Business School Press.

Dougherty, D. (1992). Interpretive barriers to successful product innovation in large firms. Organization Science, 3(2), 179-202.

Hackbarth, G. (1998). The impact of organizational memory on IT systems. In E. Hoadley \& I Benbasat (Eds.), Proceedings of the fourth Americas conference on information systems, pp. 588-590.

Hanson, M., Nihria, T., \& Tierney, T. (1999). What's your strategy for managing knowledge? Harvard Business Review, 77(2), 106-116.

Krauss, R. \& Fussell, S. (1990). Mutual knowledge and communicative effectiveness. In J. Galegher, R. E. Kraut, \& C. Egido (Eds.), Intellectual teamwork: The social and technological bases of cooperative work. Hillsdale, NJ: Erlbaum, pp. 111-144.

Madhavan, R. \& Grover, V. (1998). From embedded knowledge to embodied knowledge: New product development as knowledge management. Journal of Marketing, 62(4), 1-12.

Marshall, C. D. \& Novick, R. (1995). Conversational effectiveness and multi-media communication. Information Technology and People, 8(1), 54-79. 


\section{Macrothink}

Nonaka, I. \& Takeuchi, H. (1995). The knowledge-creating company: How Japanese companies create the dynamics of innovation. New York, NY: Oxford University Press.

Nonaka, I., Reinmoeller, P., \& Senoo, D. (2000). Integrated IT systems to capitalize on market knowledge. In G. Von Krogh, I. Nonaka, and T. Nishiguchi (Eds.), Knowledge creation: A source of value. Basingstoke: Palgrave Macmillan.

Robertson, M. Swan, J., and Newell. S. (1996). The pole of networks in the diffusion of technological innovation. Journal of Management Studies, 33, 335-361.

Sage, A. P. (1992). Systems engineering. New York, NY: John Wiley \& Sons, Inc.

Stein, E. W. \& Zwass, V. (1995). Actualizing organizational memory with information systems. Information System Research, 6(2), 85-117.

Thomas, H. D. (1997). The principles of knowledge management. Journal of Management Studies, 22, 33-36.

Walsh, J. P. \& Ungson, G. R. (1991). Organizational memory. Academy of Management Review, 16(1), 57-91. 